\title{
Graduate Accounting Students' Perception of IT Forensics: A Multi-Dimensional Analysis
}

Grover S. Kearns

University of South Florida

Follow this and additional works at: https://commons.erau.edu/jdfs|

Part of the Computer Engineering Commons, Computer Law Commons, Electrical and Computer Engineering Commons, Forensic Science and Technology Commons, and the Information Security Commons

\section{Recommended Citation}

Kearns, Grover S. (2009) "Graduate Accounting Students' Perception of IT Forensics: A Multi-Dimensional Analysis," Journal of Digital Forensics, Security and Law. Vol. 4 : No. 1 , Article 1.

DOI: https://doi.org/10.15394/jdfsl.2009.1052

Available at: https://commons.erau.edu/jdfsl/vol4/iss1/1

This Article is brought to you for free and open access by the Journals at Scholarly Commons. It has been accepted for inclusion in Journal of Digital Forensics, Security and Law by an authorized administrator of Scholarly Commons. For more information, please contact commons@erau.edu.

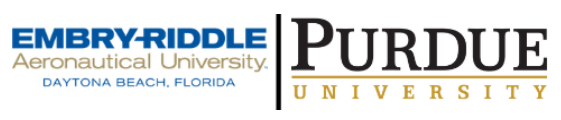

(c)ADFSL

(7) 


\title{
Graduate Accounting Students' Perception of IT Forensics: A Multi-Dimensional Analysis
}

\author{
Grover S. Kearns, Ph.D., CPA, CFE \\ College of Business \\ 140 7th Avenue South \\ University of South Florida St. Petersburg \\ St. Petersburg, FL 33701 \\ Phone: 727-553-4085 \\ Email: gkearns@stpt.usf.edu
}

\begin{abstract}
Forensics and information technology (IT) have become increasingly important to accountants and auditors. Undergraduate accounting students are introduced to general IT topics but discussion of forensic knowledge is limited. A few schools have introduced an undergraduate major in forensic accounting. Some graduate schools offer accounting students an emphasis in forensic or fraud accounting that includes instruction in forensics and information technology. When students do not view the IT topics as being equally important to their careers as traditional accounting topics, these attitudes may reduce the quality of the course. In an effort to assess student attitudes, a survey of 46 graduate accounting students was conducted to measure two dimensions - knowledge and skills and interest and enjoyment - along nine common topics found in a forensics IT course. The association of the two dimensions was then measured. Also, the relationship between IT attitudes and the nine topics was measured along both dimensions. Fifteen hypotheses are presented and tested. Results are discussed to posit what instructors can do in order to increase the quality of the class and the positive perception of IT for accounting students.
\end{abstract}

Keywords: Forensics, Accounting education, Information technology forensics, IT auditing.

\section{INTRODUCTION}

Forensics is playing a more prominent role in various disciplines and is becoming increasingly important to the field of accounting. Accountants, and to a greater extent auditors, are reliant on computer-based analytical software skills and an understanding of information technology (IT) for assurance services, assessment of corporate efficiencies, assessment of internal controls and the investigation of possible fraud. The AICPA and PCAOB have issued statements regarding auditors' increased responsibility for IT knowledge, fraud recognition and the importance of evaluating IT controls during a financial audit. The Sarbanes-Oxley Act of 2002, increased evidence of business fraud 
and advancements in IT networks and systems should lead organizations to a higher expectation of auditors' IT skills (Sumners and Soileau, 2008).

Because these emerging requirements are often the focus of various fields including information technology, law enforcement and criminal justice, it is imperative that accountants be prepared to communicate knowledgeably with others. As the demand for accountants with forensic IT knowledge increases, academic institutions must provide the basic knowledge and skills about forensic IT topics.

Recent studies have found that accounting students lacked the requisite IT knowledge and skills to perform satisfactorily in their careers positions (Ahmed, 2003; Abu-Musa, 2008). Foundation knowledge should include topics focusing on IT security issues, IT auditing, IT governance, computer based analytical methods and general forensic and fraud investigative auditing knowledge techniques. Textbooks for a foundation class today typically devote separate chapters to each of these topics (Buckoff and Schrader, 2000; Crumbley et al., 2007).

Understanding IT governance and controls is important for accountants as well as IT managers (Van Grembergen, De Haes and Moons, 2005). Internal control, as defined by COSO (1992), is the process designed to help firms achieve objectives in the effective and efficient use of resources, reliable financial reporting, and compliance with applicable laws and regulations. IT controls increase an organization's requirement for specialized knowledge and skill and are thus more costly to implement than other types of controls (ITGI, 2004; Cerullo and Cerullo, 2005). Understanding these controls is paramount to the effectiveness of both internal and financial auditors. While the adoption of computer-based auditing systems has steadily increased, a lack of IT education and background has prevented most auditors from integrating the necessary IT knowledge and skills with their professional knowledge. This impairs the ability of the auditor in conducting appropriate tests on the relevant IT controls (Li, Huang and Lin, 2007).

Possible reasons are the lack of qualified accounting instructors with a forensic IT background and an underlying feeling that forensic IT issues are less important for accounting student's traditional career paths. Thus, many accounting students are now graduating without the requisite forensic IT foundation knowledge. Another problem is that some students are less likely to perceive forensic IT knowledge and skills as important to their careers. Without proper motivation, the students may not learn and retain sufficient forensic IT knowledge to provide the future capabilities that they will need. Accounting programs may not reflect recent and significant changes in the business environment. As a result, students are not equipped with the knowledge and skills they will actually need in practice (Gabbin 2002).

The purpose of this study is to determine how graduate accounting students 
perceive the forensic IT topics and to examine the relationship between their level of interest and enjoyment in IT topics and their level of knowledge and skills with these topics.

\section{IMPORTANCE OF FORENSIC IT TO ACCOUNTANTS}

\subsection{Importance of Forensic IT Knowledge and Skills}

The Wells report showed that occupational, or business, fraud was increasing and usually involved asset misappropriation, corruption, and fraudulent financial statements (Hunton et al., 2004). Well known companies such as Marriott, Choicepoint, and Bank of America have suffered the loss of confidential customer information and data breaches (Websense, 2006). Because occupational fraud and computer related crimes are expected to grow, many universities are offering courses targeted to forensic IT (Busing et al., 2005/2006).

Auditors with forensic IT skills have been in increased demand as a result of new regulatory requirements for compliance and higher emphasis on IT governance (Hoffman, 2004). The knowledge and skills for these professionals extend well beyond those for traditional auditors and, ideally, are a blend of accounting, forensic investigative and IT knowledge and skills. Most programs in accountancy, however, have not addressed the integration of the more traditional accounting with forensics and IT knowledge and skills. Kearns (2006) notes the emergence of a hybrid auditor who is educated and experienced in all of these areas becomes a valuable resource as either an IT auditor or internal auditor.

Information technology specialization has been identified as one of the most difficult areas to staff for internal auditors (Sumners and Soileau, 2008). An analysis of 595 job listings for IT auditors found that a large percentage specifically mentioned technical skills/abilities in IT controls (31\%), networking (19\%), security (18\%), operating systems (23\%), and CAATs (15\%) (Merhout and Buchman, 2007). Additionally, 85 percent mentioned advanced certifications. Another survey revealed that internal auditors need to enhance their knowledge and skills of computerized information systems and increase understanding of systems development and acquisition activities (Abu-Musa, 2008).

Lack of forensic IT knowledge and skills can impair an auditor's ability. Continuous auditing (CA) is an increasingly important audit tool that corrects many of the deficiencies of other IT audit approaches. CA, however, often relies upon an underlying knowledge of IT and related technologies such as computer-aided auditing systems and Generalized Audit Software. Auditors who lack forensic IT knowledge will experience greater difficulty in integrating computer-aided auditing systems with their professional audit 
knowledge. This will impair the auditors' ability to independently and continuously perform tests in the CA environment (Li, Huang and Lin, 2007). Accountants must also understand forensic protocol and how to handle digital information that might be used in legal proceedings. Information assurance and proper authentication is vital in order that auditors protect the integrity of digital evidence (Duerr et al., 2004).

Studies have also affirmed that deficient IT controls weaken the organization's overall internal control structure and its ability to protect information assets (Davis et al., 2007). Because the role of IT in financial reporting systems is escalating, it is important that auditors be able to identify IT problems that affect financial reporting, evaluate the extent and nature of the problems and be familiar with steps to correct these weaknesses (Grant et al., 2008). IT control deficiencies lead to accounting and financial reporting errors (Alaali, Grant, and Miller, 2008). Companies report IT security and end-user computing controls as the major IT control problems. These include deficiencies in "segregation of IT duties, and IT policies, procedures, and documentation" (Alaali, Grant and Miller, 2008).

Many internal auditors regard technology issues as the exclusive domain of IT auditors. This perspective has created a knowledge gap between internal auditors' knowledge of a process under review and the systems that support that process. To overcome this knowledge gap, companies need to develop integrated or hybrid auditors who understand both IT general controls and application controls (Cascarino, 2007). This will require educating auditors about the IT environment, including organizational and administrative activities, infrastructure and environmental controls over how systems are linked, and physical security over IT assets and physical and logical access (Chaney and Kim, 2007). Accountants also need to understand the importance of advanced certifications. Students who are primarily interested in traditional accounting careers may wish to pursue a CPA (Certified Public Accountant), CIA (Certified Internal Auditor) or CMA (Certified Management Auditor) while those who enjoy IT topics may consider an IT Auditor certification such as CISA (Certified Information Systems Auditor). Such certifications have been shown to advance IT auditors in their careers more quickly (Wier, Hunton et al., 2000).

\subsection{Importance of Interest and Enjoyment of IT to Learning}

A requisite for success may be the enjoyment that accounting students experience with forensic IT topics. Hunton et al. (2004) posit that enjoyment of computers and technology is important to success for IT auditors. They go on to explain that IT audit engagement success is predicated on the ability to work with people in various disciplines and effectively communicate their ideas and conclusions to several levels of management. Without the foundation knowledge and skills, accountants and auditors cannot interact or communicate 
effectively with other informed personnel. Developing a positive attitude towards IT topics is important for educators of IT auditors (Cangemi, 2000). Merhout and Buchman (2007) state that the education of IT auditors requires a blending of skills and educators "should strive to cultivate such a positive attitude in their students, and they should also make their students aware of the potential opportunities in the challenging IT audit career path."

\subsection{Forensic Information Systems Course Objectives}

Important forensic IT knowledge and skills have been identified in literature. These include the general IT knowledge including the assessment, implementation, operation and control of computer resources (Hall and Singleton, 2005) and an understanding of computer-based analytical software (Hunton, Bryant and Bagranoff, 2004).

A major shift in emphasis over the past ten years has been to devote more attention to both IT threats and controls and the use of CAATs for forensic investigation. This is most likely the product of increased attention by the profession on fraud and the growing importance of IT controls on the reliability of financial data. Course objectives should include fraud and forensic techniques used by accountants to detect anomalies in the organization's financial data. CAAT software, such as ACL, represents an important analytical tool that should be part of the students' skills set. The textbooks cited typically devoted separate chapters to general IT subjects, IT security, IT controls, IT governance, and forensic and fraud auditing subjects (Whitman and Mattord, 2009).

At the undergraduate level, most programs offer a class in Accounting Information Systems that provides an introduction to information technology for accountants. It is not sufficiently broad, however, to cover forensic techniques. A second AIS class may be offered as an elective in which students are exposed to some foundation forensic knowledge and skills such as the use of computer assisted tools and techniques software (CAATs). Some graduate accounting programs offer an emphasis in forensic accounting. This normally consists of three or four courses that cover forensic and fraud accounting subjects. Few programs, however, offer more than one class in which course objectives include forensic based IT instruction.

An online investigation of both graduate and undergraduate classes that provided forensic IT course instruction revealed a common set of course objectives and textbooks normally devoted at least one chapter to each (Nelson et al., 2008; Cascarino, 2007). All of the Colleges of Business were AACSB accredited. The topics may be separated into three categories. First, the ones that represent traditional accounting topics with which students have already been introduced. Two of these are: 


\section{- Financial Auditing - Financial and Accounting \\ Analytical Methods}

Other topics represented those that are fairly new to the students and with which they have the least amount of familiarity. Three of these are:

- Information Technology

- IT Security

- Forensic and Fraud Auditing Techniques

Another set of topics represent a blend and extend the students' accounting knowledge with IT knowledge. Four of these are:

- IT Auditing

- IT Governance Frameworks
- Computer Based Analytical Methods

- Internal Control

Students were expected to possess advanced knowledge in the two strictly accounting topics. The three strictly IT topics represented areas of knowledge the student may have acquired but for which no expectation existed. The four blended areas represented topics in which the student was expected to have some knowledge that was later expanded with instruction in IT. For example, all accounting students are introduced to the concepts of internal control at the undergraduate level. However, they lack detailed knowledge of IT controls.

\section{HYPOTHESES AND METHODOLOGY}

\subsection{Hypotheses}

Fifteen hypotheses are presented. First, it was theorized that accounting students would perceive their level of knowledge and skills to be lower in both accounting and forensic IT topics than their interest and enjoyment. This is important because the students' objective is the pursuit of knowledge and skills in these areas. It is assumed that an adequate level of interest and enjoyment must exist to motivate students to pursue advanced studies. Thus, 
H1: Graduate accounting students perceived level of

knowledge and skills in accounting and forensic IT topics will

be lower than their level of interest and enjoyment in these

same topics.

Next, it was expected that students who possessed higher knowledge and skills might also be expected to display greater interest and enjoyment of forensic IT topics. Similarly, students who were interested in and enjoyed forensic IT topics were more likely to increase their knowledge and skills more highly. Other forces may motivate students to acquire knowledge and skills. In particular, those students who are highly motivated to make good grades and those who see mastery of forensic IT topics as essential to success will acquire the skills and knowledge even though their level of interest and enjoyment is not high. However, as one becomes more proficient in a subject, that subject becomes more interesting and relevant. Thus,

H2: Graduate accounting students who have a higher

perceived level of knowledge and skills in accounting and

forensic IT topics will rate their level of interest and enjoyment

in these topics more highly.

Although H2 implies a causal relationship, it cannot be determined whether higher values for knowledge and skills leads to higher interest and enjoyment or vice-versa. For this reason, a separate hypothesis is not provided. It is possible that both work at the same time: as students' knowledge and skills increase, the interest and enjoyment increases which results in greater dedication and an ensuing increase in knowledge and skills. This circular relationship is depicted in Figure 1. 


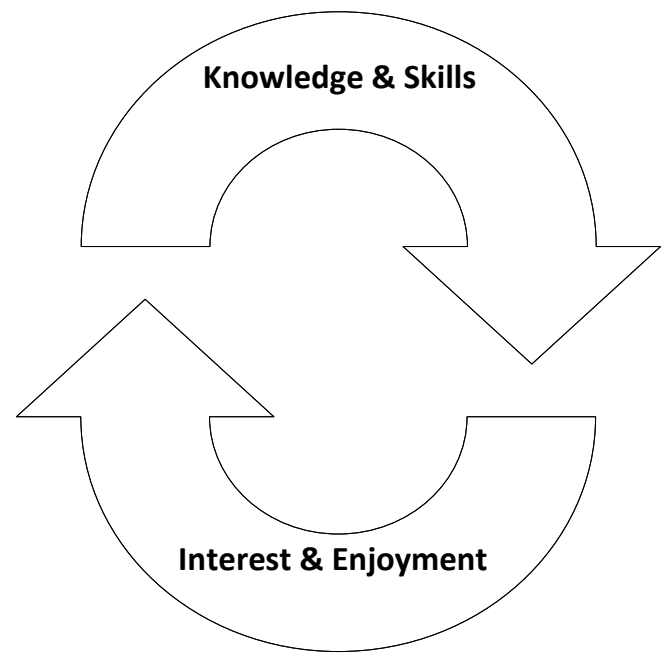

Figure 1: Circular Relationship between Knowledge \& Skills and Interest \& Enjoyment

Students who are highly dedicated to accounting or are highly focused on traditional accounting subjects might not wish to make a major commitment to another discipline such as IT and forensic analysis (Dunn and Grabski, 1998; Ravel, 1991). Therefore, it was hypothesized that students who scored highly on the two accounting topics would show lower interest in strictly forensic IT topics. Thus,

H3: Graduate accounting students who have a higher

perceived level of knowledge and skills in strictly accounting

topics will display a higher perceived level of interest and

enjoyment in strictly accounting topics.

Conversely, students who scored lower on commitment to strictly accounting topics might be interested in pursuing a related discipline and would then show a higher interest in strictly forensic IT topics. Students may find the forensic IT topics to be more interesting than traditional accounting topics or may find that they excel in these topics as compared to accounting and that forensic IT offers a more attractive alternative to the more traditional accounting topics. Thus,

H4: Graduate accounting students who have a higher perceived level of knowledge and skills in strictly forensic IT 
topics will display a higher perceived level of interest and

enjoyment in strictly forensic IT topics.

Similarly, for the same reasons as above, students who scored higher on commitment to a blend of accounting and forensic IT topics should be interested in pursuing both the accounting and IT disciplines and would be expected to show a higher interest in pursuing either advanced certification. Thus,

H5: Graduate accounting students who have a higher perceived level of knowledge and skills in a blend of accounting and forensic IT topics will display a higher perceived level of interest and enjoyment in both accounting and forensic IT topics.

Students whose attitude towards the forensic IT class is highly positive can be expected to rate both their knowledge and skills and their interest and enjoyment with forensic IT topics more highly. Knowledge and skills will shape positive attitudes because the objectives will appear more easily attainable. Interest and enjoyment may be a product of positive attitudes or actually create those attitudes. However, from $\mathrm{H} 1$, it is assumed that students will rate their K\&S lower than their I\&E particularly for forensic IT topics for which they may be expected to possess a low level of familiarity. Because students' attitudes are shaped by viewing the class as means towards obtaining an emphasis in Fraud Accounting, a positive attitude for the forensic IT topics should be positively associated with their interest and enjoyment for these topics even where their knowledge and skills are low. Thus,

H6: Graduate accounting students' Forensic IT Attitude will display a higher association with the perceived level of interest and enjoyment in strictly forensic IT topics than with the perceived level of knowledge and skills in strictly forensic IT topics.

Similarly, and for the same reasons, higher attitudes for forensic IT topics could be expected to be more highly associated with interest and enjoyment in either strictly accounting topics or a blend of accounting and forensic IT topics than for their perceived level of knowledge and skills. Although some topics have been identified as strictly accounting, students are likely to perceive their attainment of knowledge as lower then their interest. The reverse notion would not make sense. If an acceptable level of knowledge and skills had already 
been attained then interest in pursuing greater knowledge would be lower and students would not be motivated to pursue further education. Thus,

H7: Graduate accounting students' Forensic IT Attitude will

display a higher association with the perceived level of interest

and enjoyment in the accounting and blend topics than with the

perceived level of knowledge and skills in accounting and

blend topics.

The next set of hypotheses concern students' intent to pursue advanced certifications, either as a traditional CPA or as an IT Auditor.

First, because of the increased benefits of a CPA certification, it was expected that many of the graduate accounting students would intend to pursue a CPA. These students would most likely possess a lower attitude towards forensic IT topics and perceive the class as a means to acquiring knowledge that would be useful on the CPA exam. Because pursuit of a CPA requires a great investment of time, these students would be less likely to value the forensic IT topics as important to their career. For these reasons, an inverse relationship between intent to pursue a CPA and the level of forensic IT attitude could be anticipated. Thus,

H8: Graduate accounting students' Forensic IT Attitude will

be negatively associated with intent to pursue a CPA

certification.

Conversely, some students might believe that pursuit of a CPA required too high an investment and that the CPA might be devalued because of its popularity. Other students might be bored with strictly accounting topics and excited about the possibility of learning a new discipline that would make them more unique and marketable. Particularly bright students might pursue both certifications. An increased attitude towards these topics would then be associated with the intent to pursue an IT Auditor certification. Thus,

H9: Graduate accounting students' Forensic IT Attitude will

be positively associated with the intent to pursue an IT Auditor certification.

Students who scored highly on the two accounting topics along both dimensions would show lower interest in strictly forensic IT topics and a higher interest in pursuing the CPA certification. Accountants with CPAs have been shown to advance more rapidly and earn a higher salary but studying for 
the exam requires a commitment of time that might preclude pursuit of other knowledge. Thus,

H10: Graduate accounting students who have a higher perceived level of knowledge and skills in strictly accounting topics will display a higher interest in pursuing a CPA certification.

H 11: Graduate accounting students who have a higher perceived level of interest and enjoyment in strictly accounting topics will display a higher interest in pursuing a CPA certification.

Conversely, students who scored lower on commitment to strictly accounting topics might be interested in pursuing a related discipline and would then show a higher interest in strictly forensic IT topics and a higher interest in pursuing an IT Auditor certification. It might also be possible that students perceive the CPA certification as too difficult to pursue whereas a certification as an IT Auditor might be more easily attained. Studies have also shown that both internal and financial auditors who possess a certification as IT Auditor have higher average salaries and advance more quickly. Thus,

H12: Graduate accounting students who have a higher perceived level of knowledge and skills in strictly forensic IT topics will display a higher interest in pursuing an IT Auditor certification.

H13: Graduate accounting students who have a higher perceived level of interest and enjoyment in strictly forensic IT topics will display a higher interest in pursuing an IT Auditor certification.

H14: Graduate accounting students who have a higher perceived level of knowledge and skills in a blend of 
accounting and forensic IT topics will display a higher interest in pursuing an IT Auditor certification.

H15: Graduate accounting students who have a higher perceived level of interest and enjoyment in a blend of accounting and forensic IT topics will display a higher interest in pursuing an IT Auditor certification.

\subsection{Data Collection}

An anonymous survey of 46 students was used to evaluate graduate accounting students' attitude towards specific forensic IT topics and to determine if there was a relationship between their perceived level of knowledge and skills and their perceived level of interest and enjoyment of these topics. Other questions were asked to determine (1) if their attitude towards forensic IT in general affected the perceived levels of knowledge and skills and interest and enjoyment and (2) if their attitude towards forensic IT in general affected their commitment to pursue advanced certifications as a CPA or IT Auditor or both.

3.2.1 The Survey Group: Data was provided by an in-class survey, administered by the professor, to graduate students enrolled in a Masters of Business Administration program at a university in a metropolitan area in the southeastern United States. The university attracts many commuter students who are already placed in accounting careers and are completing their education. The school is accredited by the Association to Advance Collegiate Schools of Business (AACSB) which is the highest level of accreditation that can be achieved by a college of business. The class is one of four classes offered in a Fraud Accounting emphasis. The course objectives include materials that are appropriate for graduate level students who have only limited background in forensic IT and investigative techniques. Data were collected from two sections of the same class over two semesters. The classes were of approximately equal size. All of the students had undergraduate majors in accounting. The professor explained to the students that the responses were totally anonymous and could not affect their grade in any way. Because no written responses were elicited, it was not possible for the professor to discover the identity of a particular respondent. All surveys were given to an administrative assistant for data entry and the results were checked by another assistant.

Because exact age information is not available, the average age can only be approximated. Most of the MBA students are between 25 and 35 but at least 20 percent were over 35 . There was an equal distribution of male and female and nearly all commuted within a radius of 25 miles. Of the 46 students, 37 worked 
at least 20 hours each week and 27 worked full-time.

3.2.2 The Research Instrument: The complete research instrument is shown in Appendix A. Students ranked their levels on a seven-point Likert-type scale for nine different topics representing broad topic areas. Two topics referred to strictly accounting topics: Auditing and Financial \& Accounting Analytical Methods. Three topics were strictly related to forensic IT topics: Information Technology, IT Security, and Forensic and Fraud Accounting. Four topics were a blend of both: IT Auditing, IT Governance Frameworks, Computer Based Analytical Methods (CAATs such as ACL), and Internal Control. These topics were interspersed on the survey in order that the student did not unconsciously provide answers that reflected the separate groupings.

Seven topics were IT related and reflected knowledge and skills that were the principal course objectives determined annually during a needs assessment. The two others represented traditional accounting topics used for comparative purposes. It was thought that the students' knowledge and skills in these two topics would be higher and that they would also display a higher level of interest and enjoyment because they were important parts of the accounting discipline.

The blended topics represented areas that combined existing accounting knowledge and new IT knowledge. For example, the MBA students were already familiar with auditing concepts so that IT auditing was an extension of existing knowledge. Blended knowledge is normally easier to attain as it builds upon a foundation with which the student is already comfortable. Thus, it was expected that these four topics would be viewed differently by the student.

Because the survey was administered at the end of the semester, students were expected to understand the knowledge represented by each of the topics. During the course, these had been referred to frequently. Forensic and fraud auditing was the emphasis for the program and represented more sophisticated knowledge than the traditional accounting topics. IT governance represented frameworks such as COSO (Committee of Sponsoring Organizations) and CobIT (Control Objectives for IT) which were covered in the class.

The research instrument was further reviewed by two faculty members familiar with the course objectives. Comments and suggestions were used to craft the final instrument.

\section{ANALYSIS OF DATA AND RESULTS}

\subsection{Correlation Analysis}

Pearson product-moment correlation analysis was performed on the 46 observations of students in the graduate class over two separate semesters. The 24 questions measured four separate phenomena: Knowledge and Skills; 
Interest and Enjoyment; Forensic IT Attitudes; and, Intent to Pursue Advanced Certifications. Knowledge and Skills and Interest and Enjoyment were further investigated by separating the nine topics into three components of student interest: Accounting (measured by two questions), Forensic IT (measured by three questions), and Blend (measured by four questions). The survey instrument is shown in the appendix.

\subsection{Metrics and the Knowledge Index}

Metrics for the two dimensions of knowledge and skills (K\&S) and interest and enjoyment (I\&E) are shown in Table 1. A Knowledge Index has been calculated by dividing the K\&S mean by the I\&E mean. This can be interpreted as follows. If students possess equal amounts of knowledge and skills and interest and enjoyment, then the index will be 1.0. If their interest and enjoyment exceeds their knowledge and skills then the index will be less than 1.0 while the index will exceed 1.0 when their knowledge and skills exceeds their interest and enjoyment. In most cases, we would expect that I\&E would exceed $K \& S$ and the index would be less than 1.0. Except for IT Governance Frameworks, this is the case. The greatest disparity is for Forensic and Fraud Accounting. The I\&E mean is high (5.65) and the index is .69. Large disparities will also affect correlation coefficients because high levels of perceived I\&E could be associated with both low and high perceived levels of $\mathrm{K} \& \mathrm{~S}$. The index provides a measure of the relationship between I\&E and $\mathrm{K} \& \mathrm{~S}$ but not the levels of each which is provided by the means.

To test the null hypothesis that the sample means for knowledge and skills were not statistically different than the sample means for interest and enjoyment, paired two-tailed t-tests were calculated using a $95 \%$ confidence level. A low p-value for this test (less than 0.05) means that there is evidence that the difference in the two means are statistically significant (Hair et al., 1998). Results, in Table 1, show that the p-values for four of the topics to be less than 0.05. In all cases, there were large differences between the I\&E and $\mathrm{K} \& S$ means. None of these four topics represent topics that are strictly accounting related. Thus, for IT related topics, there is further evidence that students' perceive interest and enjoyment as different from their knowledge and skills. 


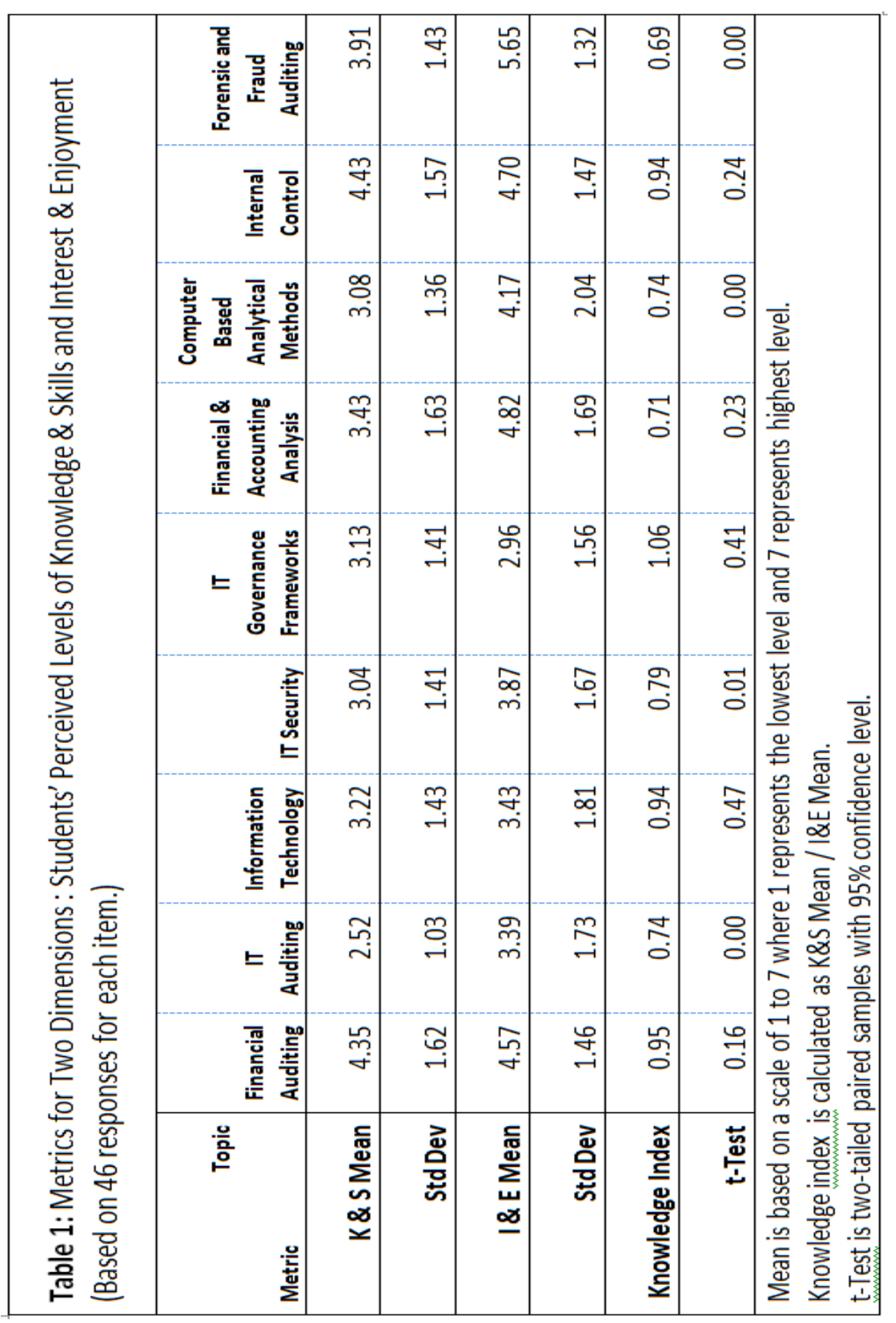

Because eight of the nine knowledge indexes were less than 1.0, H1 was supported and we can state that the perceived level of knowledge and skills in accounting and forensic IT topics will be lower than their level of interest and enjoyment in these same topics. 


\subsection{Association of Knowledge and Skills with Interest and Enjoyment}

Results for correlation of students' knowledge and skills with interest and enjoyment are shown in Table 2. Coefficients of correlation, or correlates, along the diagonal represent the strength of relationship between the knowledge and skills and the interest and enjoyment for each of the nine topics (Hair et al., 1998). Of the 81 coefficients, 71 are positive. Statistical significance is indicated for each correlate in the table. On the diagonal, there is a strong relationship for financial auditing $(r=.69)$ while IT security has the lowest relationship $(\mathrm{r}=.02)$. Six of the nine topics on the diagonal display a positive and medium to strong relationship which supports $\mathrm{H} 2$ and we can state that accounting students who have a higher perceived level of knowledge and skills in accounting and forensic IT topics will rate their level of interest and enjoyment in these topics more highly (and vice-versa by Figure 1). Surprisingly, correlates for forensic and fraud auditing were low although the mean value for I\&E was high. This indicates that high interest in this topic is related to both high and low K\&S levels for other topics. As expected, I\&E for financial auditing relates well with the $K \& S$ for financial auditing $(r=.69)$, IT auditing $(\mathrm{r}=.51)$, IT governance frameworks $(\mathrm{r}=.33)$, and internal control $(\mathrm{r}=$ $.51){ }^{1}$

\footnotetext{
${ }^{1}$ The correlation coefficient, $r$, varies in magnitude according to the strength of the relationship between the data observations. In social research, ranges of 0 to .3 are viewed as weak, .3 to .5 as moderate and above .5 as strong. Statistical significance measures the probability that the relationship is by random chance. Values greater than .10 are generally not accepted as being significant. In this study, the cutoff was .05 indicating that the likelihood of random chance was five percent or lower.
} 
Journal of Digital Forensics, Security and Law, Vol. 4(1)

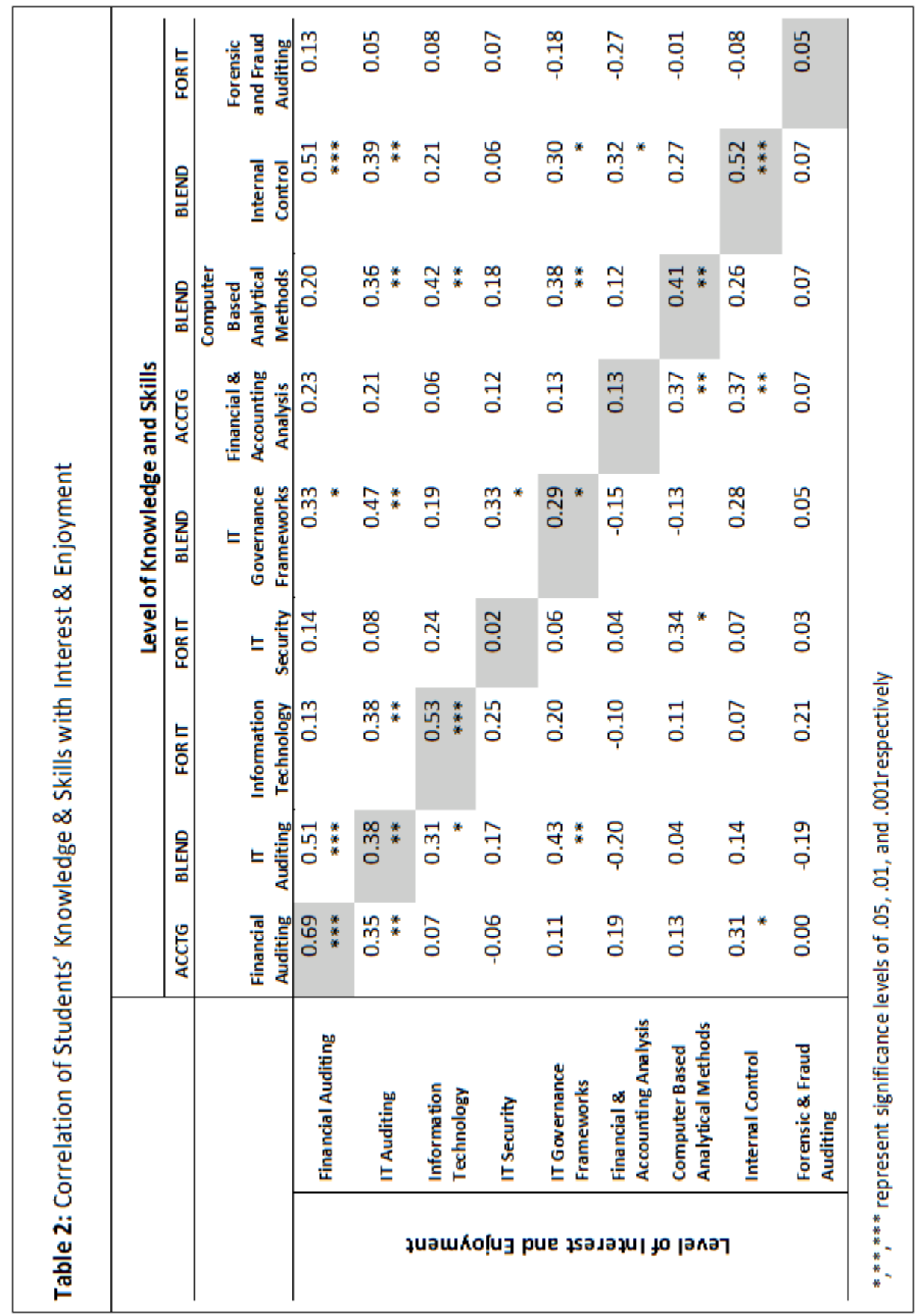




\subsection{Students with Preference for Accounting Topics}

The next set of hypotheses compared students' knowledge and skills and interest and enjoyment with preferences for accounting, forensic IT, and blended topics. The correlates for these relationships are shown in Table 3. Two topics represented knowledge that students were expected to possess prior to taking the class. These were strictly accounting topics. One was Financial Auditing and covered the audit knowledge that all undergraduate accounting majors are expected to master in a minimum of two classes. The second was Financial \& Accounting Analytical Methods that represented the quantitative and analytical skills that accountants might be expected to possess based on a minimum of four classes in Financial, Managerial and Intermediate Accounting. Knowledge and skills and interest and enjoyment were moderately related for strictly accounting topics $(\mathrm{r}=.44)$. Thus, H3 is supported and we can say that accounting students who have a higher perceived level of knowledge and skills in strictly accounting topics will display a higher perceived level of interest and enjoyment in strictly accounting topics (and vice-versa).

\subsection{Students with Preference for Forensic IT Topics}

Three topics comprised the component for strictly forensics and IT topics: Information Technology, IT Security, Forensic and Fraud Auditing. From Table 3, there was a moderate relationship $(\mathrm{r}=.35)$ between knowledge and skills and interest and enjoyment for the forensic IT component. Thus, H4 is supported and we can say that accounting students who have a higher perceived level of knowledge and skills in strictly forensic IT topics will display a higher perceived level of interest and enjoyment in strictly forensic IT topics (and vice-versa). 


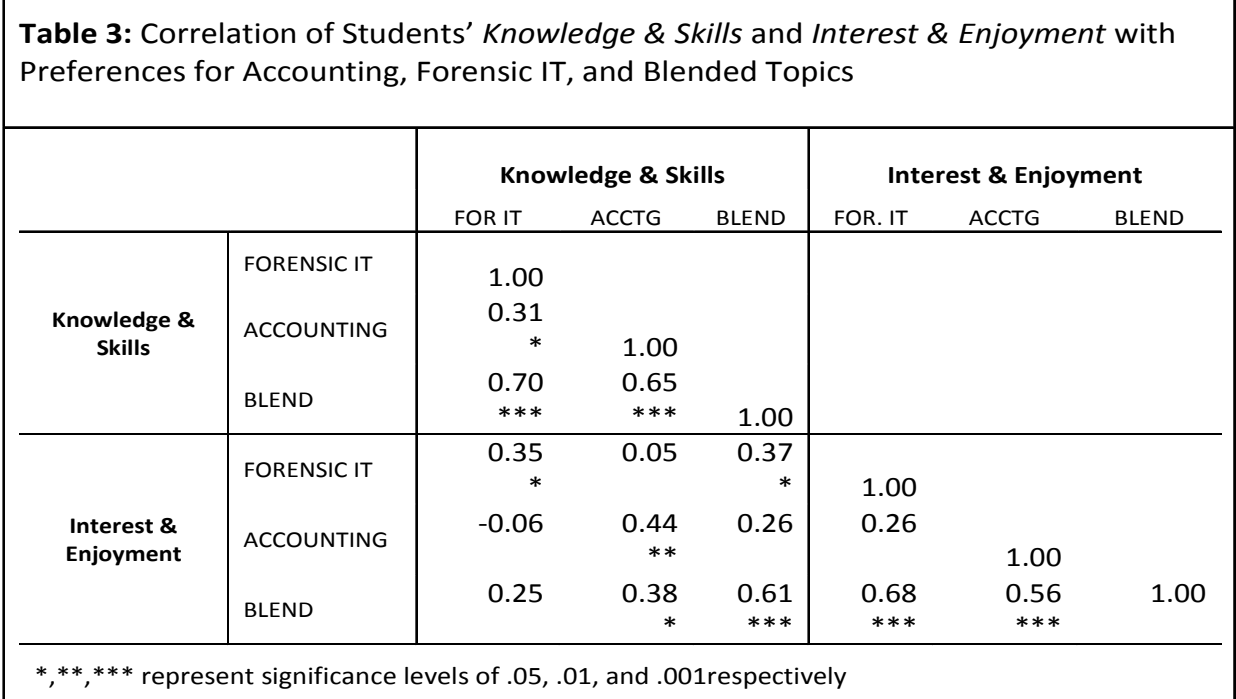

\subsection{Students with Preference for a Blend of Topics}

Four topics represented the component that is a blend of accounting and forensic IT: IT Auditing, IT Governance Frameworks, Computer Based Analytical Methods (CAATs such as ACL), and Internal Control. There was a strong relationship $(\mathrm{r}=.61)$ between knowledge and skills and interest and enjoyment for the four topics that comprised an interest in a blend of accounting and forensic IT topics. Thus, H5 is supported and we can say that accounting students who have a higher perceived level of knowledge and skills in both accounting and forensic IT topics will display a higher perceived level of interest and enjoyment in a blend of accounting and forensic IT topics (and vice-versa).

\subsection{Forensic IT Attitudes}

These hypotheses test the relationship between IT attitudes, as determined by students' interest in the forensic IT class as a means towards career goals and their perception that forensic IT skills are important to accountants, with their level of knowledge and skills and interest and enjoyment in strictly forensic IT topics. These attitudes were tested using six questions that were then correlated with the responses for the nine questions for the accounting, forensic IT and blend topics. ${ }^{2}$ The three topics that represent strictly forensic IT are:

\footnotetext{
${ }^{2}$ Students ranked nine topics representing broad areas of knowledge. These were Financial Auditing, IT Auditing, Information Technology, IT Security, IT Governance Frameworks,
} 
Information Technology, IT Security, and Forensic and Fraud Auditing. The results for knowledge and skills are shown in Table 4 and for interest and enjoyment in Table 5. The strictly forensic IT topics are shaded in both tables and discussion is limited to these topics only.

For the knowledge and skills dimension, in Table 4, results are mixed. Only 5 of the 18 correlates representing the three forensic IT topics are significant and two of these are negative. Information technology is positively associated with the belief that the class has increased overall interest in IT and forensic techniques $(\mathrm{r}=.34)$ but negatively associated with the belief that the class will help performance on the CPA exam $(r=-.36)$. IT security was positively associated with the belief that the class has increased overall knowledge $(\mathrm{r}=$ $.29)$ and would help career performance $(r=.30)$ and negatively associated with the belief that the class will help performance on the CPA exam $(r=-.46)$. Internal control was strongly associated with the belief that the class has increased overall knowledge $(\mathrm{r}=.61)$ and associated with the belief that the class will help performance on the CPA exam $(\mathrm{r}=.37)$. These correlates could indicate that the students rated their knowledge and skills as low to medium regardless of their attitudes. Table 1 showed that the K\&S means were lower than the I\&E means in all but one case.

For the interest and enjoyment dimension, in Table 5, results are highly consistent and 14 of the 18 correlates are significant and all are positive. Information technology is positively associated with the belief that the class has increased overall interest in IT and forensic techniques $(r=.28)$ associated with the belief that the class will help performance on the CPA exam $(r=.26)$. It also shows strong associations with the attitude that the class has increased overall interest in IT and forensic auditing $(\mathrm{r}=.55)$, that IT and forensic knowledge and skills are important for accountants $(\mathrm{r}=.34)$, the class will help students perform well in their career $(r=.55)$ and interest in a second forensic techniques class $(\mathrm{r}=.57)$.

Interest and enjoyment in IT security was positively associated with the belief that the class has increased overall knowledge $(\mathrm{r}=.23)$ and the belief that the class will help performance on the CPA exam $(r=.38)$. IT security shows strong associations with the attitude that the class has increased overall interest in IT and forensic audit techniques $(r=.51)$, that IT and forensic knowledge

Financial \& Accounting Analytical Methods, Computer Based Analytical Methods, Internal Control, and Forensic \& Fraud Accounting. Six questions were ranked to measure IT Attitude. These were: This class has increased my overall knowledge of IT forensics? This class has increased my overall interest in IT forensics? I believe that IT forensic skills are important for accountants? I believe this class will help me perform well in my career? I believe this class will help me perform well on the CPA exam? I would be interested in taking an IT Auditing class? 
and skills are important for accountants $(\mathrm{r}=.29)$, the class will help students perform well in their career $(\mathrm{r}=.53)$ and interest in a second forensic techniques class $(\mathrm{r}=.65)$.

Interest and enjoyment in forensic and fraud auditing was positively associated with the belief that the class has increased overall knowledge $(r=.39)$ but weakly with the belief that the class will help performance on the CPA exam (r $=.25$ ). Forensic and fraud auditing shows moderate to strong associations with the attitude that the class has increased overall interest in IT and forensic audit techniques $(\mathrm{r}=.36)$, the class will help students perform well in their career $(\mathrm{r}$ $=.48$ ) and interest in a second forensic techniques class $(r=.41)$. It was not related to the notion that IT and forensic knowledge and skills are important for accountants $(\mathrm{r}=.11)$. The large number of positive and significant correlates supports $\mathrm{H} 12$ and we can state that students' forensic IT attitude will be associated with interest and enjoyment of strictly forensic IT topics.

Because interest and enjoyment had a larger number of significant and positive associations with forensic IT attitudes, H6 is accepted and we can state that students' level of forensic IT attitudes will have a higher level of association with interest and enjoyment rather than knowledge and skills of forensic IT topics.

A similar approach is taken for the blend of accounting and forensic IT topics. Table 4 shows that 12 of the 24 correlates for the knowledge and skills dimension are significantly associated with forensic IT attitudes while Table 5 shows that 18 of the 24 correlates for the interest and enjoyment dimension exhibit significant associations. In Table 4, students with a high level of interest and enjoyment in IT auditing feel that the class has increased their overall knowledge $(\mathrm{r}=.35)$, has increased their overall interest $(\mathrm{r}=.55)$, will help them in their career $(\mathrm{r}=.42)$, and would be interested in taking a second class $(r=.76)$. Those with a high level of interest and enjoyment in IT governance frameworks feel that the class has increased their overall knowledge $(\mathrm{r}=.34)$, has increased their overall interest $(\mathrm{r}=.58)$, topics are important for accountants $(r=.35)$, will help them in their career $(r=.66)$, will help them on the CPA exam $(\mathrm{r}=.52)$, and would be interested in taking a second class $(r=.82)$. Interest and enjoyment is also highly related to attitudes for computer based analytical methods and internal control. Because there are more significant and stronger correlates for interest and enjoyment we conclude that $\mathrm{H} 7$ is supported and we can state students' level of forensic IT attitudes will have a higher level of association with interest and enjoyment rather than knowledge and skills of a blend of accounting and forensic IT topics. 
Journal of Digital Forensics, Security and Law, Vol. 4(1)

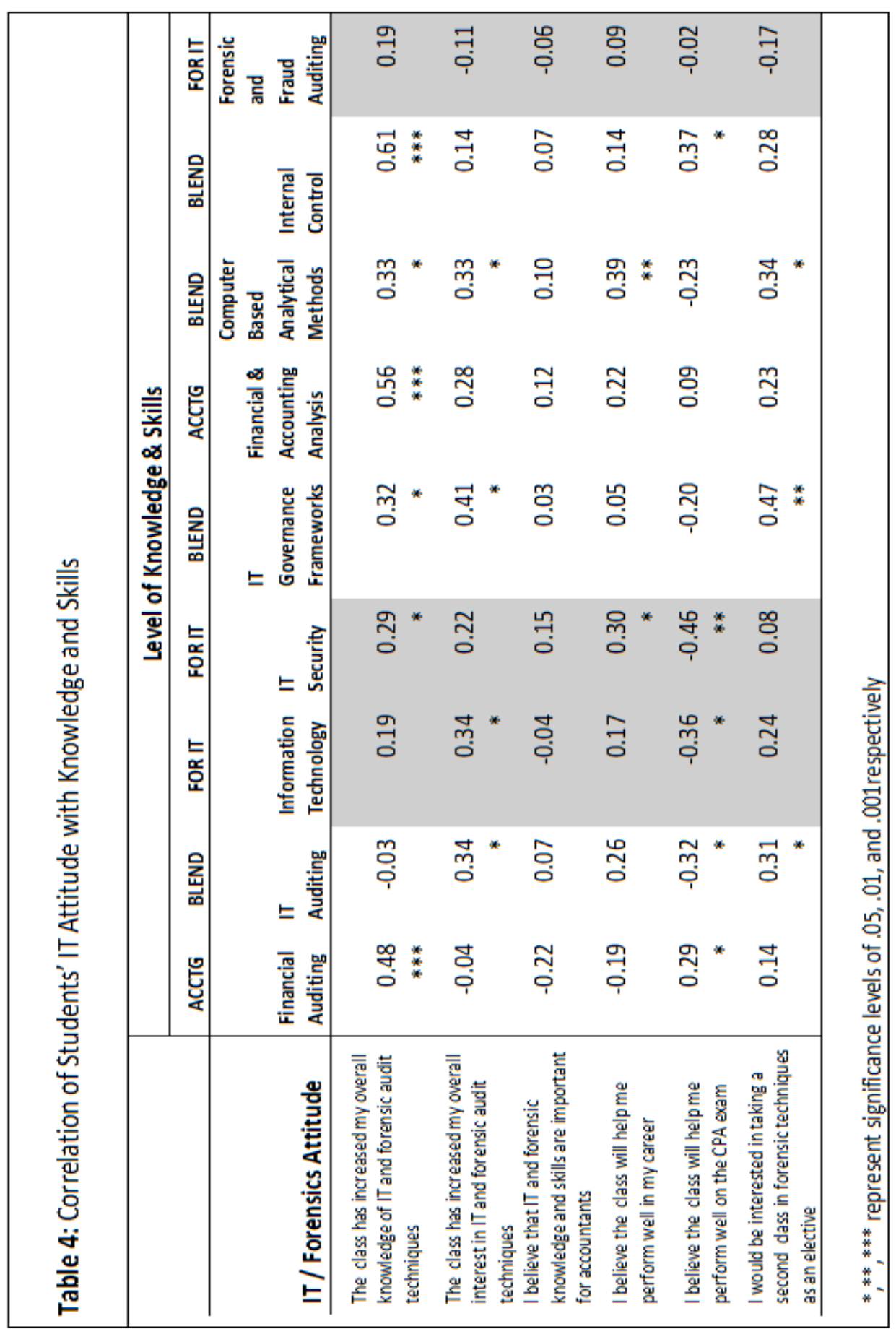


Journal of Digital Forensics, Security and Law, Vol. 4(1)

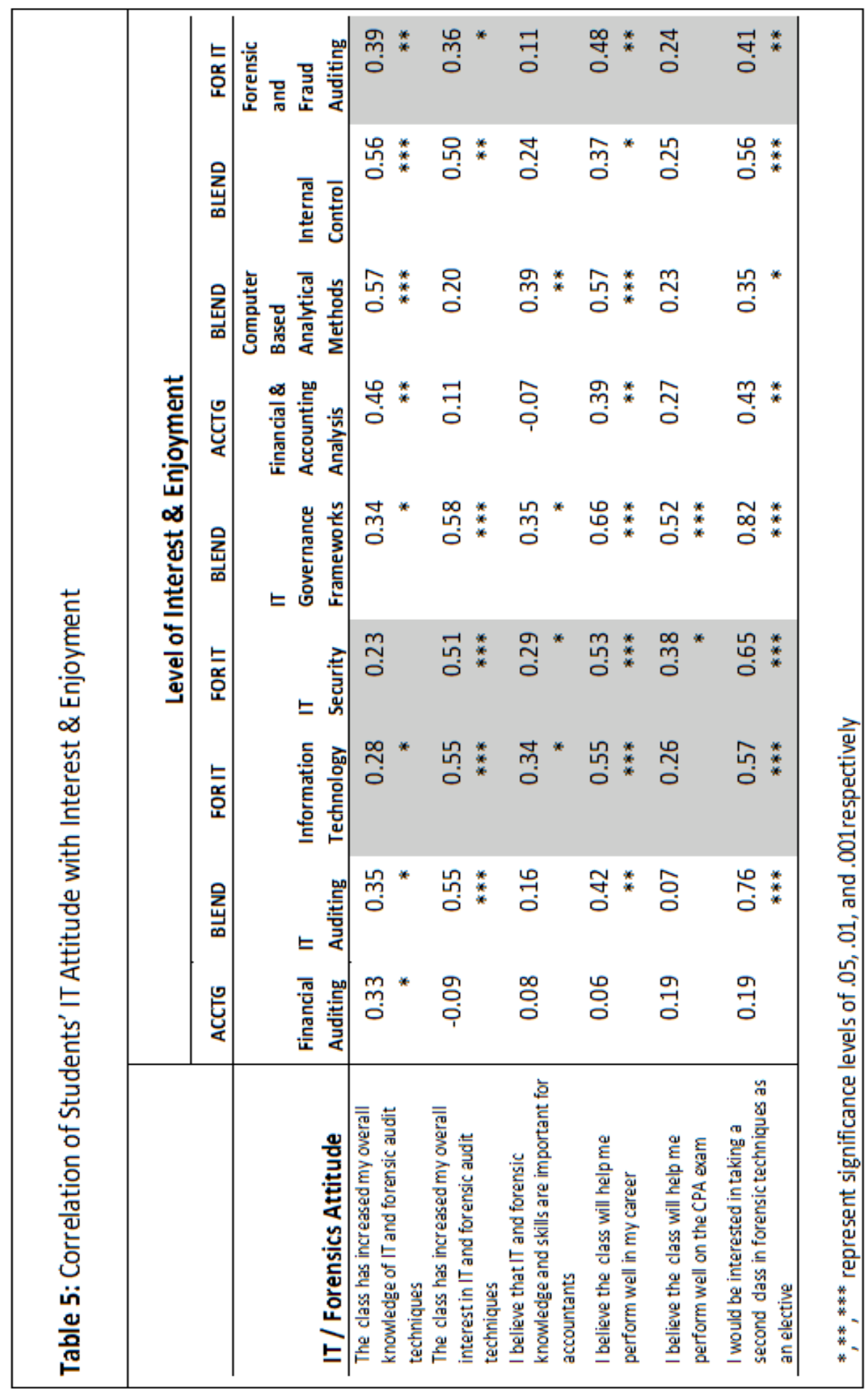




\subsection{Intent to Pursue Advanced Certification}

Students' forensic IT attitude was correlated with intent to pursue an advance certification and results are shown in the upper half of Table 6. It was expected that students who were primarily interested in pursuing a CPA would be less committed to the forensic IT topics because they represented an investment of time that students perceived as having limited benefit. Therefore, a negative association was anticipated. As expected, five of the six attitudes were negatively related with intent to pursue a CPA and four of these were significant. There was a negative association with the belief that IT and forensic knowledge and skills are important to accountants $(r=-.34)$. There is a positive but not significant association with the belief that the class would help them perform well on the CPA exam $(r=.23)$. The negative correlates support H8 and we can state that the students' will display a negative association between their forensic IT attitudes and intent to pursue a CPA.

Conversely, students who value the forensic IT topics are expected to display a positive association with intent to pursue an IT auditor certification. There were three positive and significant correlates that supported this notion. These students feel that the class has increased their overall in IT and forensic audit techniques $(\mathrm{r}=.48)$, that this knowledge is important to accountants $(\mathrm{r}=.47)$, the class will help them perform well in their career $(r=.22)$, and would be interested in taking a second course $(\mathrm{r}=.47)$. Because only three of the six correlates are significant, $\mathrm{H} 9$ is only partially supported and we can state there is some evidence that students' will display a postive association between their forensic IT attitudes and intent to pursue an IT auditor certification.

The three components were also correlated with students' intent to pursue an advanced certification along each dimension. Results are shown in the lower half of Table 6 . None of the components for either dimension was significantly related to intent to pursue a CPA and four of the six correlates were negative. Therefore, both $\mathrm{H} 10$ and $\mathrm{H} 11$ are rejected and we can state that students' will not display any significant relationship between either knowledge and skills or interest and enjoyment with intent to pursue a CPA.

For strictly forensic IT topics, there is no significant relationship for the knowledge and skills dimension with intent to pursue an IT auditor certification $(\mathrm{r}=-.14)$ but a strong and significant association for the interest and enjoyment dimension $(\mathrm{r}=.53)$. Therefore, H13, but not H12, is supported and we can state that students' who display higher interest and enjoyment in forensic IT topics will be more likely to pursue an IT auditor certification but those who display higher knowledge and skills in forensic IT topics will not be more likely to pursue an IT auditor certification.

For a blend of accounting and forensic IT topics, there is no significant relationship for the knowledge and skills dimension with intent to pursue an IT auditor certification $(\mathrm{r}=.00)$ but a strong and significant association for the 
interest and enjoyment dimension $(\mathrm{r}=.42)$. Therefore, H15, but not H14, is supported and we can state that students' who display higher interest and enjoyment in a blend of accounting and forensic IT topics will be more likely to pursue an IT auditor certification but those who display higher knowledge and skills in a blend of accounting and forensic IT topics will not be more likely to pursue an IT auditor certification.

\begin{tabular}{|c|c|c|c|}
\hline \multicolumn{4}{|c|}{$\begin{array}{l}\text { Table 6: Correlation of Students' Attitude with } \\
\text { Interest in Pursuing Advanced Certification }\end{array}$} \\
\hline \multirow{2}{*}{\multicolumn{2}{|c|}{ IT / Forensics Attitude }} & \multicolumn{2}{|c|}{ Intent to Pursue } \\
\hline & & $\mathrm{CPA}$ & IT Auditor \\
\hline \multicolumn{2}{|c|}{$\begin{array}{l}\text { The class has increased my overall knowledge of IT and } \\
\text { forensic audit techniques }\end{array}$} & $\begin{array}{r}-0.37 \\
* *\end{array}$ & 0.19 \\
\hline \multicolumn{2}{|c|}{$\begin{array}{l}\text { The class has increased my overall interest in IT and forensic } \\
\text { audit techniques }\end{array}$} & $\begin{array}{r}-0.39 \\
* *\end{array}$ & $\begin{array}{r}0.48 \\
* *\end{array}$ \\
\hline \multicolumn{2}{|c|}{$\begin{array}{l}\text { I believe that IT and forensic knowledge and skills are } \\
\text { important for accountants }\end{array}$} & $\begin{array}{r}-0.34 \\
*\end{array}$ & $\begin{array}{r}0.47 \\
* *\end{array}$ \\
\hline \multicolumn{2}{|c|}{ I believe the class will help me perform well in my career } & -0.19 & 0.22 \\
\hline \multicolumn{2}{|c|}{$\begin{array}{l}\text { I believe the class will help me perform well on the CPA } \\
\text { exam }\end{array}$} & 0.23 & -0.06 \\
\hline \multicolumn{2}{|c|}{$\begin{array}{l}\text { I would be interested in taking a second class in forensic IT } \\
\text { techniques as an elective }\end{array}$} & -0.29 & $\begin{array}{r}0.47 \\
* *\end{array}$ \\
\hline \multirow{3}{*}{ Knowledge \& Skills } & IT & -0.16 & -0.14 \\
\hline & ACCTG & -0.07 & -0.07 \\
\hline & BLEND & -0.27 & 0.00 \\
\hline \multirow{3}{*}{ Interest \& Enjoyment } & IT & 0.08 & $\begin{array}{r}0.53 \\
* * *\end{array}$ \\
\hline & ACCTG & 0.01 & -0.03 \\
\hline & BLEND & -0.25 & $\begin{array}{r}0.42 \\
* *\end{array}$ \\
\hline
\end{tabular}




\section{DISCUSSION}

This study has three primary contributions. First, it provides information that will assist instructors of graduate accounting students in a forensic techniques class to improve students' attainment of forensic IT knowledge of skills. Second, it provides important information about the relationship between two dimensions of learning: knowledge and skills and interest and enjoyment. Third, it provides a tested instrument for use by researchers and practitioners.

Instructors of forensic IT techniques need to know what motivates their students to learn and how they perceive the topics that typically support course objectives. Student responses can be expected to vary along different dimensions including their existing level of IT knowledge and skills when they enter the class. Some students who are highly interested in the traditional accounting topics and are intent on pursuing a CPA may view the class as a required subject that provides important knowledge and skills but one that does not provide interest and enjoyment or they may view it as less important to their career objectives than other classes in their major. In any case, information that assists the instructor to improve the students' overall performance is important. Unfortunately, there has been scant attention to learning motivators at this level.

Nine topics, representing forensic IT and accounting topics, were used to determine if there existed a relationship between perceived IT knowledge and skills and interest and enjoyment. Fifteen hypotheses explored the relationships between the two dimensions and attempted to determine if particular topics accounting, forensic IT, a blend of accounting and forensic IT - were more likely to appeal to students and be associated with the intent to pursue advanced certifications. Students' attitudes towards the class were measured to determine the association with these topics and along the two dimensions. Ten of the hypotheses (H1, H2, H3, H4, H5, H6, H7, H8, H10, H11 and H12) were supported, one was partially supported (H9), and four were rejected (H10, H11, $\mathrm{H} 12$, and H14).

Results showed a positive and strong relationship between the two dimensions. Whether knowledge and skills leads to higher levels of interest and enjoyment or vice-versa or both cannot be proven. We can only state that a causal relationship appears to exist based upon study data. The purpose of the forensic IT class is to increase knowledge and skills. However, it is reasonable to assume that the level of interest and enjoyment will make it easier and be an important motivator for the students to acquire such knowledge. It will also motivate them to seek further knowledge in the future. Knowing that the relationship is strong should prompt instructors to increase efforts to improve students' interest and enjoyment. These facilitators have not been addressed in this paper and could be the subject of future research. Furthermore, while it was shown that the relationship between the two dimensions was stronger 
when measured within the components (accounting, IT, blend), the correlates were mainly medium to strong between components. This leads us to believe that even those students who are primarily interested in either accounting or forensic IT will be spurred to learn other topics if they have sufficient interest and enjoyment. Thus, the level of interest and enjoyment is an important condition to the creation of knowledge and skills.

Data also revealed that neither knowledge and skills or interest and enjoyment for the three components had significant associations with intent to pursue a CPA. However, the intention to pursue a CPA certification was very high: out of the 46 responses, 36 students stated that they did intend to pursue the certification and 10 stated that they may pursue it. Thus, the response was high regardless of the value of the component and the resulting correlates could be expected to be low.

The association of both knowledge and skills and interest and enjoyment for forensic IT and blend components with intent to pursue an IT Auditor certification are particularly strong. This evidence is important because the demand for IT auditors is increasing and provides accounting students an attractive alternative to a traditional accounting career path.

The relatively high means for the interest and enjoyment of the blend topics, as shown in Table 1, also highlights the importance of blending existing with new knowledge. Students appear to accept knowledge more readily if it is more comprehensible. If the knowledge set described by the strictly IT topics could be blended with existing accounting knowledge, it might be accepted more readily by the students.

IT Attitude was found to be an important predictor of interest and enjoyment for all three forensic IT topics but not as much for the knowledge and skills dimension. The forensic IT topics represent the more challenging topics for accounting students. Because there were six questions measuring IT attitude, there were a total of 36 correlates (six questions, three topics, and two dimensions as shown in Tables 4 and 5). Since 19 of the 36 relationships were significant and many in the moderate to strong range, the evidence shows how important attitude is to learning. For this reason, instructors should find opportunities to stress the importance of the topics to accounting careers. The various ways in which this can be done would be an important topic for future research. Overall, IT Attitude had stronger associations with all nine topics for interest and enjoyment than for knowledge and skills. A positive attitude is clearly associated with interest and enjoyment.

5.1.1 Benefits for Researchers and Practitioners: Both researchers and practitioners can benefit from the study results. Researchers can replicate the study results to support the reliability and validity of the instrument. They can also examine ways in which instructors of forensic IT topics can increase the students' interest and enjoyment of the topics. Practitioners can use the 
instrument to determine the level of their own students' interest and enjoyment and to assess their IT attitudes. They can also benefit from knowing that increasing the interest and enjoyment is likely to increase the knowledge and skills outcomes. Furthermore, instructors can provide those students who are interested in pursuing IT auditor certifications with information on how to advance their IT knowledge and direct them to informational resources.

Students' attitudes were inversely related to intent to pursue a CPA. This could signify that students who are dedicated to the traditional accounting topics and are intent on pursuing a CPA will possess lower attitudes and view the class as less important than other classes that are more directed towards achieving traditional knowledge and skills and supporting CPA topics. Thus, the instructor may wish to spend more time early in the class educating students about how the forensic IT topics can help accountants in traditional jobs and how the course content is directly related to portions of the CPA exam.

Accounting departments at AACSB accredited schools regularly perform a needs analysis to systematically identify course objectives for each class. Course objectives reflect the knowledge and skills that students must attain to successfully complete the class. These are determined by input from various sources: syllabi from similar courses at other universities, discussions with instructors at conferences and workshops, an evaluation of market demand, the advisory board, and prerequisites for subsequent courses. Assessment of success includes exams, homework assignments and term papers. While vital to the overall program goals, needs analysis and subsequent assessment are outside the scope of this paper. However, this study addresses the students' perceived level of knowledge and skills in specific topics that reflect important course objectives. This information is important to assessing the success of the course in achieving its goals and in identifying gaps in knowledge.

A list of suggested approaches for improving outcomes and closing the knowledge gap is shown in Table 7. Instructors of both undergraduate and graduate classes may benefit although some are specific to the MBA class in IT Forensics Investigations for Accountants.

Finally, for future studies, the research instrument should be altered to reflect any changes in course objectives. Properly crafted, it can be an important tool for assessing needs and improving course outcomes. 


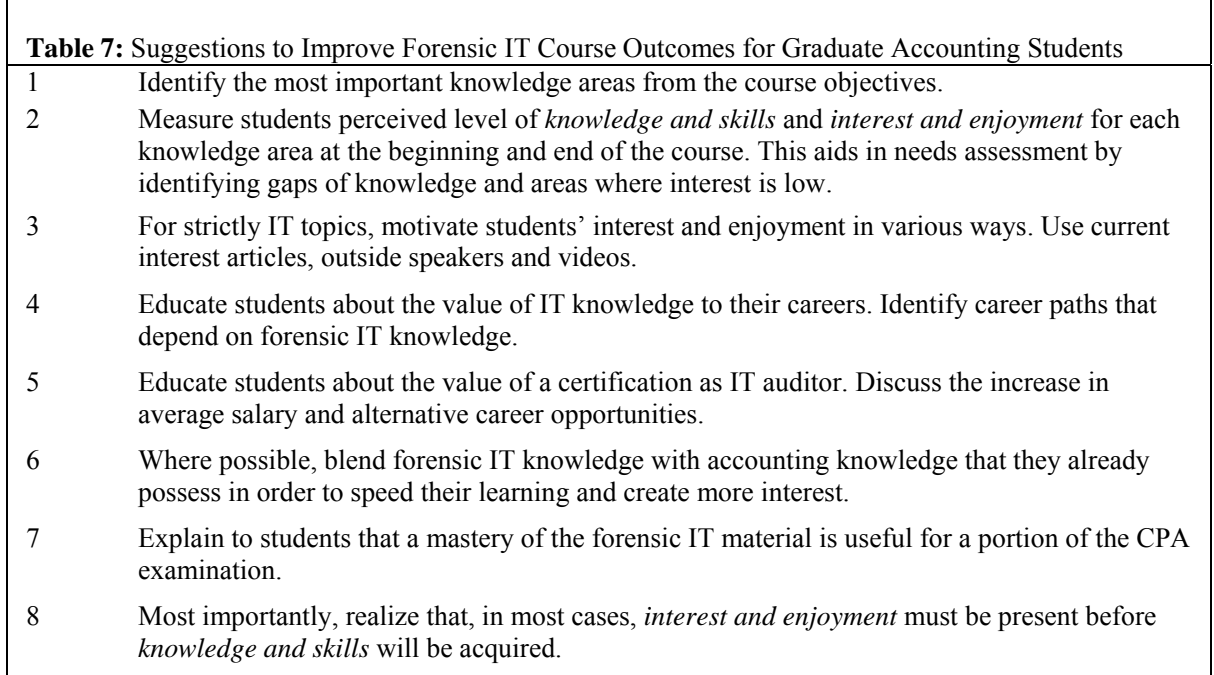

5.1.2 Study Limitations: There are several limitations to the study. First, the sample size of 46 students is small. A larger number of observations would provide higher levels of reliability and validity. However, sample size was sufficient to conduct tests of significance. Second, results represent the students' self-reported perceived level for each question. Often, with selfreporting, respondents will supply socially acceptable answers. However, anonymity was expected to adequately address this problem. Self-reporting can also lead to variability induced by individual egos. Over a large sample size, this is assumed to average out. One of the purposes of the survey was to gauge students' interest and enjoyment for each of the topics and this can only be accomplished by self-reporting. Third, the nine topics were broad without subsets. Internal control, for example, encompasses a broad knowledge set that is addressed in a number of accounting classes. However, the survey was administered two weeks prior to the end of the semester and students had developed an understanding of what was represented by each of the topics and could be expected to evaluate their levels of knowledge and skills accordingly.

\section{CONCLUSIONS}

Instructors of forensic IT for graduate accountants might improve attainment of course objectives by encouraging students' interest and enjoyment of course topics. They can also assess attitudes and guide students towards furthering their IT education where interest exists. Communicating the importance of course topics to students will be particularly meaningful to those students who do not perceive the importance of the topics to their own career or to pursuing 
advanced certification. Some students will continue to see the course as necessary to furthering a traditional accounting career and will not develop a high level of interest in forensic IT topics. On the other hand many students will embrace the forensic IT topics and be interested in pursuing an advanced certification as IT auditor. Because the course objectives are broad and the technology can be highly sophisticated, students may not perceive that they have attained even a moderate level of knowledge and skills in certain topics. In this study, students ranked their knowledge and skills for several IT topics as low (IT auditing mean $=2.52$, Table 1 ). This may reflect a deficiency in attaining these objectives or simply a problem with perception. For an introductory forensic IT course, objectives are rather broad and sufficient time for in-depth discussions of all topics is not available. For this reason, it is imperative that the syllabus objectives adequately reflect the most appropriate mix of topics and that class time be allotted in the most optimal manner. Where students are also required to advance their skills in analytical software, such as $\mathrm{ACL}$, this task is imposing.

By creating interest and enjoyment in the forensic IT topics and stressing the importance to the students' careers, instructors are most likely to achieve success with the course objectives and improve students' learning outcomes. 


\section{APPENDIX}

\section{IT INVESTIGATIVE TECHNIQUES FOR AUDITORS: MBA ACCOUNTING STUDENT IT INTEREST SURVEY STRICTLY CONFIDENTIAL - DO NOT PlACE YOUR NAME ON THIS SURVEY}

Instructions: The purpose of this survey is to gather information that will allow your professor and the Program of Accountancy to make informed choices about the materials included in the curriculum. Your answers are confidential and only summary information will be reviewed and evaluated. Under no circumstances will an individual student's responses be identified or used as part of his or her grade. Please answer all questions as accurately as possible.

Do you plan to pursue advanced certifications such as a CPA, CMA, or CIA?

YES MAYBE NO

Would you consider pursuing a certification as an IT Auditor?

YES MAYBE NO

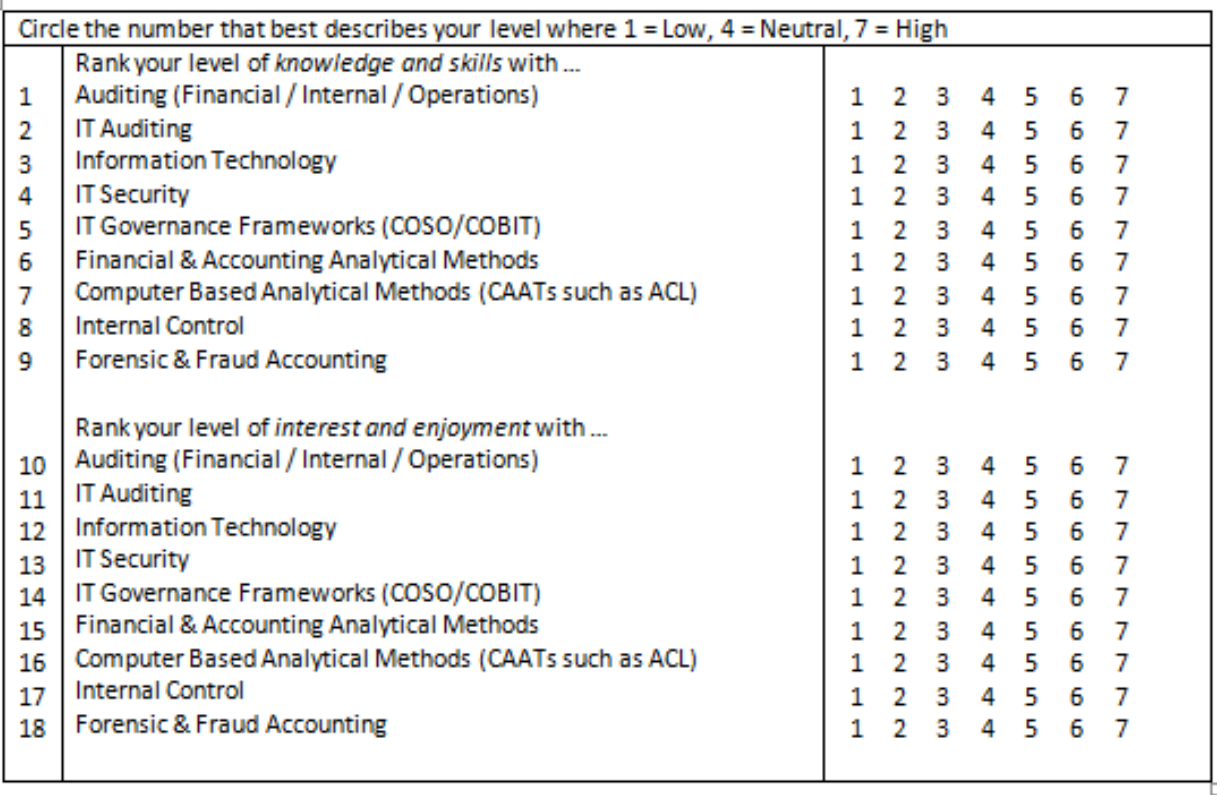

Circle the number that best describes your level of agreement where 1 = Highly Disagree, $7=$ Highly Agree

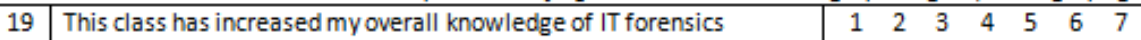

20 This class has increased my overall interest in IT forensics $\quad \begin{array}{lllllll}1 & 2 & 3 & 4 & 5 & 6 & 7\end{array}$

21 I believe that IT forensic skills are important for accountants $\quad \begin{array}{lllllll}1 & 2 & 3 & 4 & 5 & 6 & 7\end{array}$

22 I believe this class will help me perform well in my career $\quad \begin{array}{lllllll}1 & 2 & 3 & 4 & 5 & 6 & 7\end{array}$

23 I believe this class will help me perform well on the CPA exam $\quad \begin{array}{lllllll}1 & 2 & 3 & 4 & 5 & 6 & 7\end{array}$

24 I would be interested in taking an IT Auditing class $\quad \begin{array}{lllllll}1 & 2 & 3 & 4 & 5 & 6 & 7\end{array}$ 


\section{REFERENCES}

Abu-Musa, A. (2008) Information Technology and Its Implications for Internal Auditing; An Empirical Study of Saudi Organizations. Managerial Auditing Journal, Vol. 23 (5), pp. 438-466.

Ahmed, A. (2003) The Level of IT/IS Skills in Accounting Programmes in British Universitities. Management Research News, Vol. 26 (12), pp. 20-58.

Alali, F., Grant, G. H. and Miller, K. C. (2008) IT Control Deficiencies that Impact Financial Reporting. Internal Auditing, Vol. 23 (4), pp. 28-37.

Buckoff, T.A. and Schrader, R.W. (2000) The Teaching of Forensic Accounting. Journal of Forensic Accounting, Vol. 1 (1), pp. 135-146.

Busing, M.E., Null, J.D. and Forcht, K.A. (Winter 2005/2006) Computer Forensics: The Modern Crime Fighting Tool. The Journal of Computer Information Systems, Vol. 46 (2), pp. 115-119.

Cangemi, M. P. (2000) (ed.) What Recruiters and Staffing Agencies Say about Trends in IS Auditing, Information Systems Control Journal, Vol. 5, pp. 43-45.

Cascarino, R. (2007) Auditor's Guide to Information Systems Auditing. John Wiley \& Sons, Inc., Hoboken, NJ.

Cerullo, M. and Cerullo, M. J. (2005) How the New Standards and Regulations Affect an Auditor's Assessment of Compliance With Internal Controls. www,isaca.org/jonline. February 10, 2009.

Chaney, C. and Kim, G. (2007) The Integrated Auditor. The Internal Auditor, Vol. 64 (4) pp. 46-52.

Crumbley, D.L, Heitger, L.E. and Smith, G.S. (2007) Forensic and Investigative Accounting, $3^{\text {rd }}$ ed. CCH Incorporated, Chicago, IL.

Davis, C. Schiller, M. and Wheeler, K. (2007) IT Auditing: Using Controls to Protect Information Assets. McGraw-Hill, New York.

Duerr, T.E., Beser, N.D. and Staisiunas, G.P. (2004) Information Assurance Applied to Authentication of Digital Evidence. Forensic Science Communications, Vol. 6 (4).

Dunn, C. and Grabski, S. (1998) The Effect of Field Dependence on Conceptual Modeling Performance. Advances in Accounting Information Systems, Vol. 6, pp. 65-77.

Gabbin, A.L. (2002) The Crisis in Accounting Education. Journal of Accountancy, Vol. 193 (4), pp. 81-86.

Grant, G. H., Miller, K. C. and Alali, F. (2008) The Effect of IT Controls on Financial Reporting. Managerial Auditing Journal, Vol. 23, (8), pp. 803-823. 
Hair, J. F., Anderson, R. E., Tatham, R. L. \& Black, W. C. (1998) Multivariate Data Analysis with Readings, 5th ed. Prentice Hall, Englewood Cliffs, New Jersey.

Hall, J. A. and Singleton, T. (2005) Information Technology Auditing and Assurance, $2^{\text {nd }}$ ed., South-Western College Publishing, Mason, OH.

Hunton, J. E., Bryant, S. M. and Bagranoff, N. A. (2004) Core Concepts of Information Technology Auditing, John Wiley \& Sons, Inc., Hoboken, NJ.

Hoffman, T. (2004) IT Auditors Coveted, Hard to Find. Computerworld, Vol. 38 (18), pp. 1-16.

ITGI (2004) IT Control Objectives for Sarbanes-Oxley. www.isaca.org/sox. January 8, 2009.

Kearns, G. S. (2006) A Curriculum for Teaching Information Technology Investigative Techniques for Auditors. Journal of Digital Forensics, Security and Law, Vol. 1 (4), pp. 9-28.

Li, S., Huang, S. and Lin, Y. G. (2007) Developing a Continuous Auditing Assistance System Based on Information Process Models. The Journal of Computer Information Systems, Vol. 48 (1), pp. 2-13.

Merhout, J. W. and Buchman, S. E. (2007) Requisite Skills and Knowledge for Entry-level IT Auditors. Journal of Information Systems Education, Vol. 18 (4), pp. 469-477.

Nelson, B., Phillips, A., Enfinger, F. and Steuart, C. (2008) Guide to Computer Forensics and Investigations, $3^{\text {rd }}$ ed. Thomson Course Technology, Boston, MA.

Ravel, V. (1991) Perspectives on Students' Teaching Evaluations of AIS Courses. The Journal of Information Systems, Vol. 5 (2), pp. 62-72.

Sumners, G. E. and Soileau, J. S. (2008) Addressing Internal Audit Staffing Challenges. Information Systems Management, Vol. 25 (2), pp. 3-11.

Van Grembergen, W., De Haes, S, and Moons, J. (2005) Linking Business Goals to IT Goals and COBIT Processes. Information Systems Control Journal, Vol. 4, pp. 18-21

Websense (2006) Security Trends Report, Second Half 2005. www.websense.com/global/en/. December 11, 2008.

Whitman, M. E. and Mattord, H. J. (2009) Principles of Information Security, $3^{\text {rd }}$ ed. Thomson Course Technology, Boston, MA.

Wier, B., Hunton, J. E. and Beeler, J. D. (2000) The Impact of Higher Education and Professional Certification on the Careers of Information Systems and Non-Information Systems Auditors. Information Systems Control Journal, Vol. 5, pp. 38-41. 
Journal of Digital Forensics, Security and Law, Vol. 4(1) 